\title{
Ecological compensation: from general guidance and expertise to specific proposals for road developments
}

\author{
Ana Villarroya'*, Jesper Persson², Jordi Puig' \\ ' Department of Zoology and Ecology, University of Navarra, c/ Irunlarrea s/n, 31008 Pamplona (Navarra), Spain \\ 2 Department of Landscape Management, Design and Construction, Swedish University of Agricultural Sciences (SLU), \\ P.O. Box 66, SE-230 53, Alnarp, Sweden \\ * Author to whom correspondence may be addressed. E-mail: avillarroya@alumni.unav.es
}

\begin{abstract}
The main scientific bibliography addressing the rationale behind ecological compensation is reviewed in order to examine general guidelines. This contains interesting general guidance on how to implement compensation, and provides the basis for future developments in compensation practice. On this basis, we propose a further step in compensation practice, advancing compensation proposals or rules for specific kinds of projects and contexts, focusing on road projects in the Spanish Environmental Impact Assessment (EIA). Three main residual impacts of roads are identified which usually remain uncompensated for: the loss of natural and semi-natural land use, the increase in emissions resulting from any new road, and the fragmentation, severance or barrier effect on the landscape and its wildlife. To counteract these, four proposals, or "rules", are advanced: conservation of natural and semi-natural land use area, conservation of dominant plant species physiognomy, compensation for emissions, and the rule of positive defragmentation.
\end{abstract}

Keywords: Environmental Impact Assessment; offsets; sustainability; no net loss; net ecological gain

\section{Introduction}

Human development often causes negative impacts on natural assets. Changes in land use, such as urbanization or road construction, inevitably cause damage to the natural or ecological aspect of the environment, to a greater or lesser extent (Dale et al., 2000; Forman and Alexander, 1998; Forman et al., 2003; Hansen et al., 2005; Kalnay and Cai, 2003; Vitousek et al., 1997). For some areas it may be said that "we are creating a built infrastructure at the expense of natural infrastructure" (Madsen et al. 20 I0, p.l).

The existing regulations on nature conservation and Environmental Impact Assessment (EIA), among other regulatory tools, seek to restrict these negative impacts. Moreover, there is a growing sense that promoting positive change is a better way to move towards sustainability than by merely minimizing the negative effects that development may have on the natural environment (Pope et al., 2004). Following this line of thought, it is increasingly argued that development should produce 'no net losses' or even achieve 'net gains' in the natural quality of the environment, thus counteracting the cumulative impact of development that would otherwise gradually reduce this quality (Hayes and Morrison-Saunders, 2007; van Merwyk and Daddo, undated). Even if these impacts appear insignificant when regarded separately, their progressive accumulation in the environment leads to greater losses in the long term (Race and Fonseca, 1996).

The so-called 'mitigation hierarchy' has been widely recommended as a way to seek no-net-loss on the natural quality of areas with development projects. It establishes that the optimal sequence to confront environmental impacts should be: (I) avoid, (2) 
minimize, and (3) compensate the damage that the project is expected to cause (Darbi et al., 2009; Dolan et al., 2006; EU, 200 I; USC, 2002).

Compensatory measures are the last sequential step in this mitigation hierarchy. They are thus the last possible chance to achieve the 'no net loss' or 'net gain' goals (Gibbons and Lindenmayer, 2007; luell et al., 2003; McKenney, 2005; Moilanen et al., 2009; Rowe et al., 2009; ten Kate et al., 2004). Compensation may either reinstate the natural value that is lost even after avoidance and minimization have been thoroughly implemented (Cuperus et al., 1996; luell et al., 2003), or improve the original quality of the damaged environment (EPA, 2006; Kuiper, 1997; McKenney, 2005).

Although the idea is increasingly accepted, present-day compensation practice is still far from reaching these goals. For example, recent studies on EIA Records of Decision (RODs)' in Spain showed that compensation was frequently overlooked. Moreover, when actually implemented, compensatory measures were not designed, chosen or selected in a way that was adequately reasoned (Villarroya and Puig, 20 I0). For instance, no attempt was found across the RODs at justifying the degree of equivalence between residual impacts (i.e. those impacts which cannot be avoided nor reversed) and the measures proposed to compensate them.

Although the concept and rationale underlying compensation may be easy to understand, the choice and design of specific offsets to be implemented in each development project is usually a harder task. This constraint is inherent to the nature of compensation, as there is a wide open range of suitable measures for each case. When it comes to specifying compensation measures, two particular issues give rise to problems:

a. Location. Cuperus et al. (2002) stated that while mitigation measures are physically tied to the infrastructure, compensation may take place anywhere. Whether the reader agrees with this view or not, it is obvious that a suitable place to implement compensatory measures has to be found, which must be adapted to each case.

b. Equivalence to the damaged feature. The correspondence between the negative effects and the compensatory measures to counterbalance them may be difficult to weigh up (van Bohemen, 1998). The equivalence will depend on several factors (including environmental goals and impact characteristics) which are not always easy to gauge and balance.

The design of compensatory measures seems to demand a case-by-case solution. At the same time, to address compensation practice as consistently as possible, some general accepted guidance and expertise are needed to somehow justify to a greater or lesser extent the decisions that are taken along the compensation process (see Kuiper, 1997).

This article focuses on ecological compensation, which can be defined as "the substitution of ecological functions or values that are impaired by development" (Cuperus et al., 200 I). It examines published recommendations given to guide its implementation, and the rationale behind them. It aims to collect and discuss the guidance and expertise concerning compensation in order to channel it towards particular compensation processes. Even though our proposals center on specific problems that have been

\footnotetext{
' $A$ ROD is the publicly available document where the approving agency presents the main factors that were contemplated to reach the final decision on every project, including the practical means to avoid or minimize environmental harm.
} 
registered for Spain, our approach addresses general issues that may be of application to other contexts.

\section{Theory: guidance and expertise on the design of compensatory measures}

The design of compensatory measures has to fit the particularities of each case. It is therefore not easy to find valid general guidance, suitable for a wide range of particular cases, on how to select the kind of compensation to be applied. In fact, what Race and Fonseca (1996) observed several years ago remains true today, since it still cannot be said that there is a universally accepted standard regarding this matter.

Several authors have provided guidance on the design, choice or implementation of compensatory measures. They explain the different rationales for choosing one option or another when it comes to location of offsets and equivalence to the damaged features. Some recommend one option over the rest, while others just explain the advantages and/or disadvantages of each choice.

Regarding these issues (location and equivalency), the current literature describes the following options:

- When it comes to the location of the offsets to be implemented, compensation may be labeled as "in-site" or "off-site", depending on whether the measures are located within or outside the effect zone of the project (Brinson and Rheinhardt, 1996; Cuperus et al., 1999).

- Regarding the equivalency of habitats or species, compensation may be either in-kind or out-of-kind, depending on whether it is aimed at the same assets (habitat, species or functions) that were impaired, or at different ones (Brinson and Rheinhardt, 1996; Cuperus et al., 1999).

To put together the advantages and disadvantages that have been identified for each of these options, a bibliographic review was conducted. We looked for publications that addressed environmental compensation, using "environmental compensation", "ecological compensation", "compensatory mitigation", "offsets", "no net loss" and "net gain" as the main search terms for the title, abstract, keywords or main text in both scientific and general databases. After that initial selection, we established whether the documents included any discussion or recommendations on how to decide the location and kind of offsets. Only those documents that explained the rationale behind their proposals were selected. Other papers not specifying this rationale were set aside. As a consequence, legal texts were not taken into account in this case, since although they sometimes provide some recommendations on offset location and/or equivalence, they do not focus on the rationale behind this guidance. Papers that just cited other authors' discussion or recommendations on compensation guidance (without adding anything new) were not selected. Fifteen publications were found that met all these requirements, which included explanations of pros/cons and sometimes also recommendations on how to decide the location of offsets and/or their equivalency to the impaired natural features (see list in Table I). 


\begin{tabular}{lll} 
Year & Resource & References \\
\hline 1996 & Scientific papers & $\begin{array}{l}\text { Race and Fonseca, 1996; Brinson and Rheinhardt, I996; Hashisaki, } \\
\text { 1996; Mitsch and Wilson, I996 }\end{array}$ \\
1998 & Scientific paper & van Bohemen, 1998 \\
2001 & Book & National Research Council, 200I \\
2003 & Report & luell et al., 2003 \\
2004 & Report & ten Kate K et al., 2004 \\
2004 & PhD dissertation & Cuperus, 2004 \\
2005 & Report & McKenney, 2005 \\
2006 & Scientific paper & Morris et al., 2006 \\
2006 & Book chapter & Reijnen and Foppen, 2006 \\
2007 & Scientific paper & Hayes and Morrison-Saunders, 2007; Latimer and Hill, 2007 \\
2010 & Scientific paper & Kiesecker et al., 20 I0 \\
\hline
\end{tabular}

Table I. Selected documents for review

Thirteen publications addressed how to choose the location of compensatory measures. While seven advise on-site over off-site compensation, two advise the contrary. Among the fifteen documents reviewed, eight were found to address what might be the equivalency for impacted habitats or species. Six of them included some clear recommendation, always prioritizing in-kind over out-of-kind compensation. The implementation of in-kind and on-site offsets, whenever possible, is the most widely mentioned recommendation among the publications reviewed. Nevertheless, no consensus has been reached, and discussion will doubtless continue on this matter.

Arguments for or against alternative compensation options, briefly summarized in Table 2, are reviewed below in more detail. Even though they may seem to be opposed to each other when considered in the abstract, the joint consideration and final choice of which of these arguments should be prioritized in each case may help to strengthen the rationale for compensation proposals in specific cases. 
Compensation option

\section{Equivalence}

damage -

compensation

\section{In-kind}

Perspective

Ecological

Technnical

Political

Out-of-kind Ecological

Technical

Ecological

Location of the compensatory

measures

In-site Ecological

Arguments in favor

It has the greatest potential to minimize disruption of ecological remaining functions

They compare easily to the original situation

It is easier for the public to understand

Allows further flexibility to focus on conservation priorities

Technical

Political It is easier to get public acceptance

Off-site Ecological Allows further flexibility to focus on conservation priorities and connecting to larger systems

Compensation sites are not adversely influenced by proximity to human-altered places

Technical Increases the chances of success through careful selection of suitable areas and the linkage of several compensation projects in one single larger one
Arguments against

There are natural elements which cannot be re-created

Not easy to define in practice what "in-kind" means

Difficulties to establish the correspondence between damaged features and compensatory measures

Depends completely on the availability of adequate places within the affected area

Difficulties when choosing the location

Table 2. Summary of arguments for or against each compensation option, following the reviewed bibliography 
Advantages of in-kind offsets:

- They have the greatest potential to minimize local disruption of ecological functions, especially when located on-site. This is of great importance in areas where significant ecological linkages and functions have not been completely lost (Race and Fonseca, 1996). This approach may be particularly of use when compensation seeks to prevent certain species, habitats, or ecosystems from being progressively degraded while others receive all the benefits of the compensatory measures (Hayes and Morrison-Saunders, 2007).

- They compare easily to the original situation. It is easier to balance the measures to implement when the proposed offsets are ecologically similar to the damaged features (ten Kate et al., 2004). It has been proposed, for example, that the product of the surface of the impacted area by its natural value should remain constant, through compensation, when we compare this value before and after intervention. This kind of rule is easier to apply (including calculations) through in-kind compensation (van Bohemen, 1998). Also, when compensation aims at no-net-loss (luell et al., 2003), in-kind compensation seems the easiest way to propose, justify and follow a full and equivalent replacement of losses (McKenney, 2005), even when carrying out offsets through conservation banks (Latimer and Hill, 2007).

- It is easier for the public to understand the rationale behind them. The more dissimilar the compensatory measure is to the impaired asset, the more justification will be necessary for the public. Even straightforward like-for-like offsets frequently need scientific inputs and third party valuations to ensure their credibility. Out-of-kind measures will generally require a broader justification effort (ten Kate et al., 2004).

Shortcomings regarding in-kind offsets:

- It may not be easy to define, in practice, what "in-kind" means. How similar does the implemented measure have to be to the damaged feature to be considered in-kind compensation? The technical difficulty in measuring some parameters (e.g. biodiversity values) may hamper the comparison between damaged features and offsets (Hayes and MorrisonSaunders, 2007).

- There are natural elements which cannot be technically re-created (Morris et al., 2006), in which case in-kind compensation is not possible at all.

Advantages of out-of-kind offsets:

- They allow conservation options other than strict replacement of the damaged values. Out-of-kind measures may be the only option when inkind compensation is not possible, or be more appropriate when they offer the opportunity to concentrate all the compensation efforts either on the most important natural value among the damaged by the development (luell et al., 2003), or on boosting some natural value that was not even damaged by the development but which is of greater importance for the region than the recovery of the damaged ones (McKenney, 2005; ten Kate et al., 2004; Kiesecker et al., 20 I0).

Shortcomings of out-of-kind offsets: 
- The main difficulty regarding out-of-kind compensation usually arises when trying to assess the correspondence between the damaged feature and the compensatory measure. Usually, elaborate justifications are used. There are no fixed ratios for out-of-kind compensation, and most existing methods are not yet fully developed (McKenney, 2005; Morris et al., 2006; ten Kate et al., 2004). This problem may also affect in-kind compensation (see above), although to a less important degree.

Advantages of on-site offsets:

- They have great potential to recover precisely the disrupted ecological functions (Race and Fonseca, 1996). Location, in landscape, may be of utter importance to recover the impaired values (Race and Fonseca, 1996), as is the case when we try to re-connect severed environments or wildlife routes (Brinson and Rheinhardt, 1996).

- They take advantage of the habitat conditions a priori demanded for inkind compensation, which increases the possibilities of success. These conditions may be necessary to get the best like-for-like replacement (Latimer and Hill, 2007).

- Compensation benefits accrue to the affected area. This rule is widely accepted by most offset policies (McKenney, 2005), and other authors (Morris et al., 2006).

- They are met with greater public acceptance or support. Even when it focuses on recovering natural values, the compensation process should pay attention to social issues such as fairness and the sense of ownership by local communities, to increase its chances of success (ten Kate et al., 2004).

Shortcomings of on-site offsets

- The carrying out of on-site compensation will always depend on the availability of suitable places where it can be implemented within the affected area. Since the range of locations may be very limited, it is not always possible to find an appropriate one.

Advantages of off-site offsets:

- They may boost ecological values beyond the affected area (McKenney, 2005; ten Kate et al., 2004). The enlargement of valuable off-site ecosystems through compensation may yield more ecological benefits than the mere sum of 'patchy' or isolated on-site compensation practices (Hashisaki, 1996; McKenney, 2005; Reijnen and Foppen, 2006). Moreover, off-site compensation makes it possible to bring together the compensation efforts corresponding to several projects into a chosen area of ecological value. This has been proposed as a potentially successful strategy (Cuperus, 2004; Reijnen and Foppen, 2006) that may also be put into practice through mitigation banking (NRC, 200I). Landscape-level planning of conservation priorities is a key element in deciding the location in these cases.

- They make it possible to locate compensation sites away from places altered by humans now or in the future. Some species are sensitive to anthropogenic disturbances such as visual contact, noise, fires, and 
domestic pet encounters (Cuperus, 2004; Latimer and Hill, 2007; McKenney, 2005; Mitsch and Wilson, 1996). For example, an attempt at improving a bird habitat nearby a road may have a limited effect (Reijnen and Foppen, 2006). Future developments induced near present-day projects may threaten today's on-site compensation efforts (Latimer and Hill, 2007).

Shortcomings of off-site offsets

- The difficulty of location choice. A central question when designing off-site compensatory measures is how to decide their location. We are frequently advised to choose it in accordance with national or regional conservation plans or initiatives (Kiesecker et al., 2010), which should (ideally) identify and prioritize the best locations for nature conservation or improvement. However, few countries have developed functional tools to link compensation practice to conservation strategies effectively (Blundell and Burkey, 2006). The same problem may be applied to out-of-kind compensation in most cases. Habitat banking could be another useful tool in this sense, but it has not yet been developed in many countries.

\section{Discussion: from general guidance and expertise to more specific proposals}

The arguments described above may be summarized in two broad, general recommendations:

- In-kind and on-site compensation may be more appropriate when the priority is to keep the local natural or ecological conditions as close as possible to their original state, or to restore them. This option commonly meets with greater local public acceptance, and so it is more easily put into practice.

- Out-of-kind, off-site compensation provides the flexibility to make measures converge with broader (i.e. national or regional) conservation strategies. They also allow compensation when in-kind, on-site compensation is not possible.

But the reach of these general recommendations is limited, if we focus on specific situations. To translate the general 'no-net-loss' or 'net-gain' objectives into specific compensation practice in particular projects, it is necessary to clarify further how these general goals have to be interpreted and applied in particular cases.

When specific cases are confronted, "one-size-fits-all" solutions may not be desirable since they would not be realistic (BBOP, 2009b). But some guidance may be of help insofar as it may clarify the rationale behind specific proposals (why, how, and to what extent compensation is necessary), and so gradually strengthen the practice of compensation. In any case, the compensation process should be flexible and make it possible to devise solutions that are site-specific, at least to some extent (ten Kate et al., 2004). How, then, can general guidance be further specified to take account of particular circumstances of country, scale, ecology, project, public or site? Although this occurs less frequently than may be desirable, certain regulations do provide some recommendations on the location and/or equivalency of ecological compensation measures for certain 
projects or places, by giving preference to some of the options described above (Madsen et al., 20 I0; McKenney and Kiesecker, 20 I0; ten Kate et al., 2004).

In Europe, Directive 2004/35/EC (on environmental liability) specifies that when designing offsets (which are referred to as 'compensatory remediation'), in-kind compensation must be considered first, thus prioritizing those actions which provide "natural resources and/or services of the same type, quality and quantity as those damaged" (EU, 2004). On the other hand, Directive 92/43/EEC establishes that compensatory measures shall guarantee the overall coherence of Natura 2000, which is mostly interpreted as a demand for in-kind compensation (EU, 1992; Madsen et al., 20 I0). These attempts, debatable as they may be, provide a second level of guidance which complements the scientific literature on compensation practice, which might be applicable in certain projects (see Annex III in Directive 2004/35/CE), and across Natura 2000 spaces in Europe. However, these cases do not seem to be very frequent. In fact, it has recently been reported that current laws and public policies rarely provide an explicit interpretation of broad 'no-net-loss' or 'net-gain' objectives (BBOP, 2009a; Brownlie and Botha, 2009).

Moreover, in order to move towards improved sustainability, effective compensation should be progressively extended to all projects that cause residual impacts on natural assets, and not only to certain projects or areas (see PAA, 1993).

If we do not get down to specifics, general objectives (e.g. "sustainability") remain less meaningful. Further specification concerning the objectives of ecological compensation should be developed for each of those project types that could potentially damage the environment, and which currently lack well-developed guidance or practice. If we clarify the way broad 'no-net-loss' or 'net-gain' goals may be interpreted in practice, it will become easier to choose and justify appropriate compensatory actions. And if these specific proposals (or other equivalent ones) are not followed, we will have clear indicators of how we have failed to attain sustainability in particular projects, because of neglecting compensation.

In the following section we make some proposals in this direction, focusing specifically, as an example, on proposals for road construction projects that cause negative residual impacts on areas not belonging to the Natura 2000 network. As specific recommendations may vary from one country to another, we have designed the proposals with the case of Spain in mind. These proposals may therefore need to be adapted to the needs or contexts of other countries. For instance, wetlands are common natural features in countries like Sweden, but not in Spain. If this approach were made for Sweden, the basic goals would probably focus more specifically on wetlands.

\section{Proposals on compensation practice for road projects in Spain.}

Generally speaking, projects of the same kind usually affect a characteristic set of natural functions or features of the areas where they are carried out, which may be more or less vulnerable depending on the specific natural and geographical context. Roads impact the environment they cross, as new dams, or irrigation projects do, but each of them impacts the environment in a characteristic way.

In order to set basic goals towards achieving 'no-net-loss' or 'net-gain' objectives, we propose to identify those impacted natural features or functions that can be most easily assessed and are most frequently or deeply damaged by the kind of project we are dealing with (i.e. road development) and set them as priority targets for compensation. 
With roads in mind, we identify three main residual impacts easily understood as such: the loss of natural and semi-natural land use area, the increase in emissions as a result of the new road, and the fragmentation or barrier effect on the landscape and its wildlife.

Although compensation should eventually meet the ultimate 'no-net-loss' or 'netgain' goals and address all of the impacts, less ambitious objectives may be a more feasible target as a first stage in developing compensation practice for specific projects, while leaving the implementation of stricter practices for the future. Although current practice needs to be improved, we agree with Hayes and Morrison-Saunders (2007) in saying that "attempting to establish offsets, even if they do not live up to the idea of no net loss, must be more desirable environmentally than development in the absence of any attempt at conservation".

With this context in mind, four basic rules are proposed to be applied in every road project that causes residual impacts (outside the Natura 2000 network) in Spain. They do not ensure sustainability, but their implementation would certainly make progress in this direction; and failure to apply them would indicate that sustainability is at risk.

\subsection{The rule of conserving natural and semi-natural land use area}

The construction of a road transforms the land where it is located, both directly and indirectly, causing habitat loss and changes in land uses, among other effects (Forman and Alexander, 1998; Riiters and Wickham, 2003). It is also commonly argued that changes from natural scenarios towards more anthropic land uses usually lead to negative ecological impacts (Allan, 2004; Foley et al., 2005; Poschold et al., 2005; Sala et al., 2000; Tong and Chen, 2002). If these transformations accumulate in the environment, the area of natural and semi-natural land use (i.e. natural habitats, or land uses that support some forms of wildlife) is diminished as the overall percentage of built area increases. From an ecological standpoint, this leads to a decrease in the total quality of the area. Ecological compensation should seek to counteract this effect by keeping the proportion "natural and semi-natural surface/built surface" as constant as possible.

As a more specific proposal, we suggest that at least the total area directly occupied by the new road (i.e. the surface that is paved or reshaped, and physically transformed into a road and its adjacent new slopes) should be retrieved somewhere else (e.g., in some adjacent uncultivated land area), by restoring this land to its former and more natural uses (e.g. forest or shrub land), in return for the original land already lost. In other words, we should retrieve somewhere all the hectares of forest, shrub land or grassland, pastures or crop land that have been taken up and replaced by the new road or else justify how we will compensate for them.

In short, the proposal consists of not taking for granted any loss in area of any kind of natural or semi-natural land use, but rather measuring the area lost to the new road, and replacing it. If we remove ten hectares of mature forest, then we should create at least ten new hectares of mature forest or their equivalent. When surface conservation does not prove feasible, some effort might be put into the improvement of the ecological quality of selected areas, along the lines recommended by Cuperus et al. (1999). In applying this rule, we should also pay due attention to the vegetation physiognomy of the areas lost, particularly to its degree of maturity or, at least, to its size, which brings us to the next rule proposed. 


\subsection{The rule of conserving dominant plant species physiognomy}

Vegetation is a basic component of ecosystems, and a key feature to appraise their value. Each kind of plant formation has a specific ecosystem. Their respective ecological and economic values differ from each other (see Costanza et al., 1997), but they depend heavily on the species composition and plant physiognomy. Dominant species physiognomy indicates, in most cases, the minimum time span required for the associated ecosystem to become established. This is of relevance to compensation practice as "generally the longer the time required for the habitat to develop, the more difficult it will be to compensate for impacts" (Cuperus et al., 1999). Forest restoration and regeneration are processes that require a long time to develop, and that may have a high failure rate if not carefully designed (Chazdon, 2008). This means that compensation for impacts on mature habitats such as forests probably requires far more effort in terms of time and money than it would for grassland.

With a view to implementing this simple, first approach to compensation practice, a raw classification may be used focusing just on the overall vegetation physiognomy of each formation (e.g., forest, woodland, shrub land, and grassland). We propose that compensatory measures should at least ensure that the global proportions of vegetation physiognomies are kept constant (unless any external conservation priorities require the contrary). Roughly speaking, if ten hectares of mature forest are removed, ten hectares of mature forest should be effectively created in compensation: not just ten hectares of shoots or newly planted small trees. The systematic requirement that this target should be met might well act as a deterrent, to prevent unnecessary damage to high-size vegetation during project implementation.

\subsection{The rule of compensation for emissions}

Air quality is a major concern nowadays, especially as far as the increase of greenhouse gases, such as $\mathrm{CO}_{2}$, is concerned (IPCC, 2007). Road construction does not cause significant increases in exhaust fumes by itself, but it may induce rises in the volume of traffic (Cervero, 200 I; Goodwin, 1996; Goodwin and Noland, 2003) which ultimately lead to higher emissions which have major effects on air quality and atmosphere (Hoor et al., 2009; Koffi et al., 20 I0).

Precisely because it is an induced impact rather than a direct one, the increase in gas emissions is often forgotten as a target for compensation in road projects (see Villarroya and Puig, 2010). There are two main reasons why we find it essential to propose the offsetting of emissions as a basic goal in compensation associated with road projects. On the one hand, it is assumed that new roads lead to more traffic, and traffic emissions always have a negative impact on air quality. So it can be said that the increase in greenhouse emissions is an unavoidable impact always linked to road projects. On the other hand, this kind of impact is not only local, but has a global reach. This characteristic means that it is not only ecologically, but also ethically necessary to provide some compensation, since the project is negatively affecting communities that cannot enjoy any of its benefits. For these reasons we think all road projects should compensate their foreseen induced emissions, either through direct action (i.e. carbon sequestration projects implemented by the developer) or, when that proves not feasible, through already existing tools such as carbon markets. 


\subsection{The rule of positive defragmentation:}

Roads cause the fragmentation of those landscapes they cross. Fragmentation has repeatedly been pointed out as one of the main threats to biodiversity (Fahrig, 2003; Jongman, 2002; Saunders et al., 1991; Trocmé, 2006; Trocmé et al., 2003). Although mitigation measures are increasingly implemented to reduce this impact (e.g., through wildlife passages), the net effect of a new road will always be a higher level of fragmentation. As a final rule, we propose that some distinctive action beyond mitigation should be taken, to ensure that any new road project implements a positive defragmentation initiative. The following example could clarify our proposal.

The A-10 motorway is located in the Euro-Siberian area of northwest Navarre, Spain. It runs along the flat bottom of a wide valley surrounded by steep forested mountain sides. Forests across the area consist mainly of beech (Fagus sylvatica), with common oaks (Quercus robur) in the valleys and white oaks (Quercus humilis) on the sunniest slopes. The forested areas of Urbasa-Andia and Aralar (Figure I) have been long intersected by agricultural uses, local roads, and a railway. The construction of the A-10 motorway worsened the separation between the Aralar and the UrbasaAndia forests, especially because one of the remaining forested patches stretching across the gap between the mountain sides was fenced off by the motorway (Figures 2 and 3). A positive defragmentation initiative could have consisted of using a small viaduct or false tunnel to join the two sides of the patch, and so avoid its severance (a fragmentation minimization measure), and also of extending the forested patch to narrow or even close the gap between the Aralar and Urbasa-Andia forests (a positive defragmentation initiative), as shown in Figure 3.

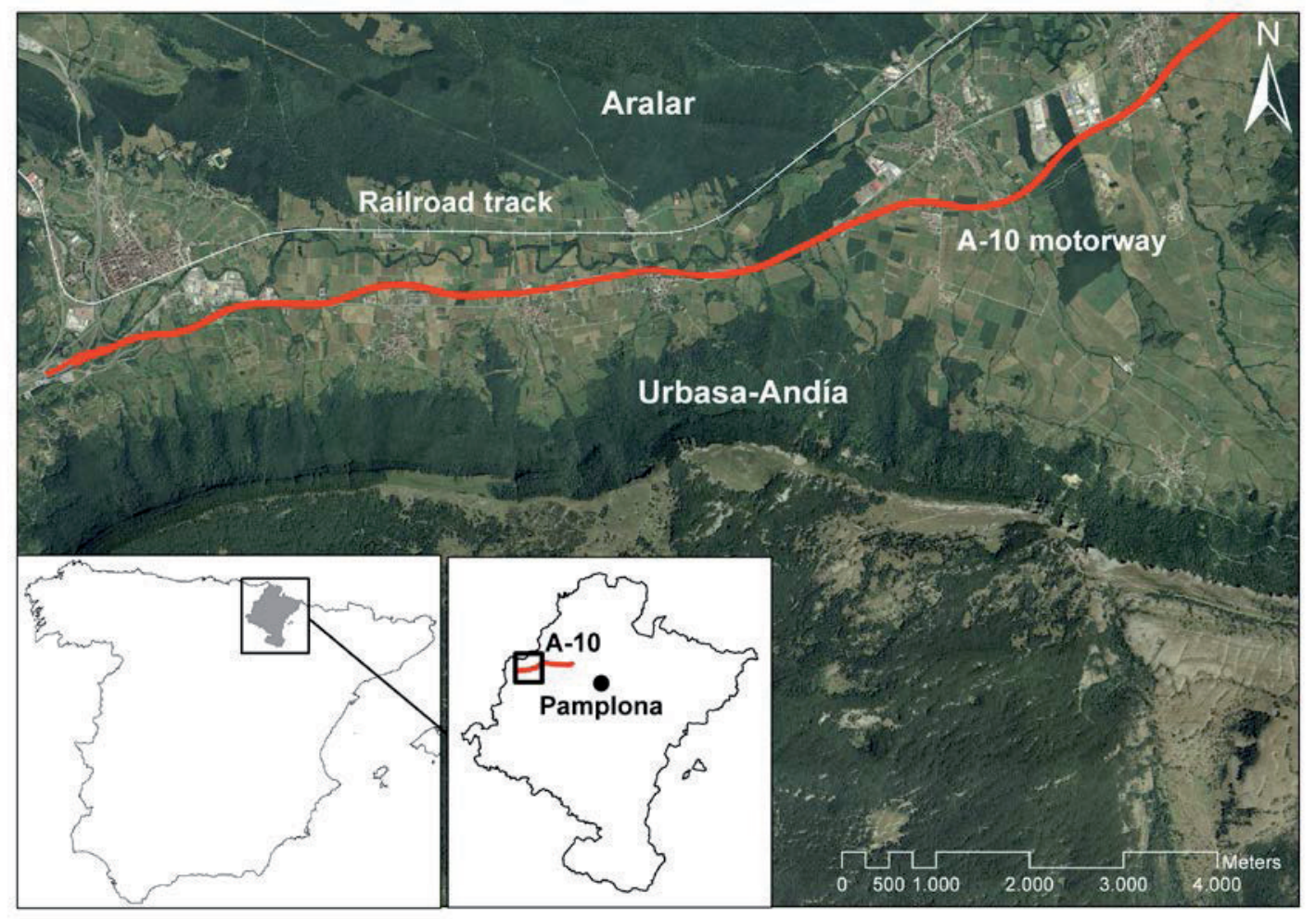

Figure I. Location and general view of the area, showing the A-10 motorway in red. The city of Alsasua can be seen on the eastern edge of the picture. The orthophotography shows the division that human activities have caused between the Aralar and Urbasa-Andia forested areas. 


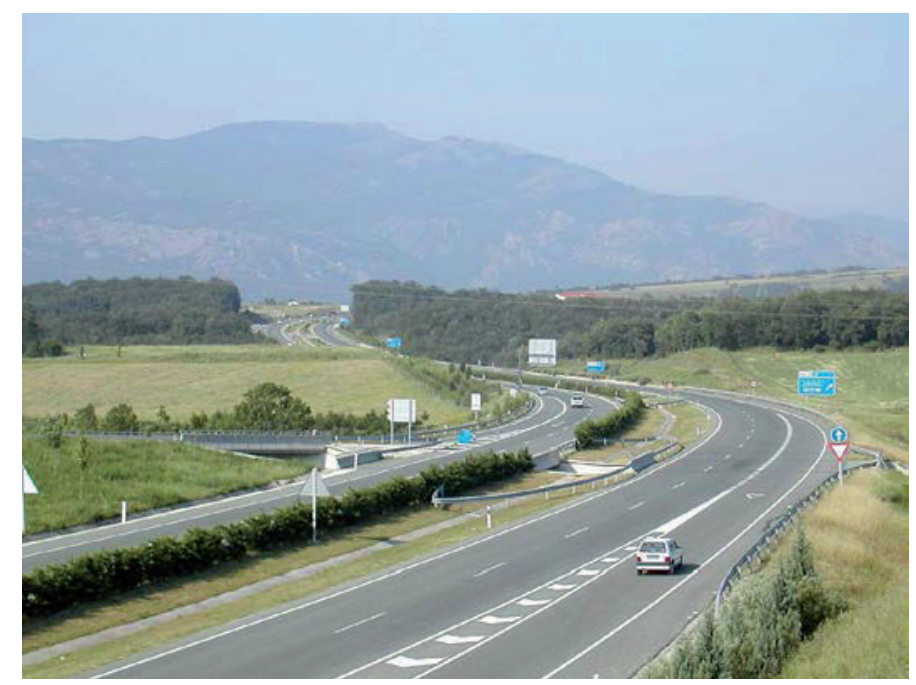

Figure 2. The photograph shows clearly how the A-10 motorway crosses one of the remaining forested patches, stretching across the gap between the Aralar and Urbasa-Andia mountain sides. Photographer: Luis Sanz Azcarate.

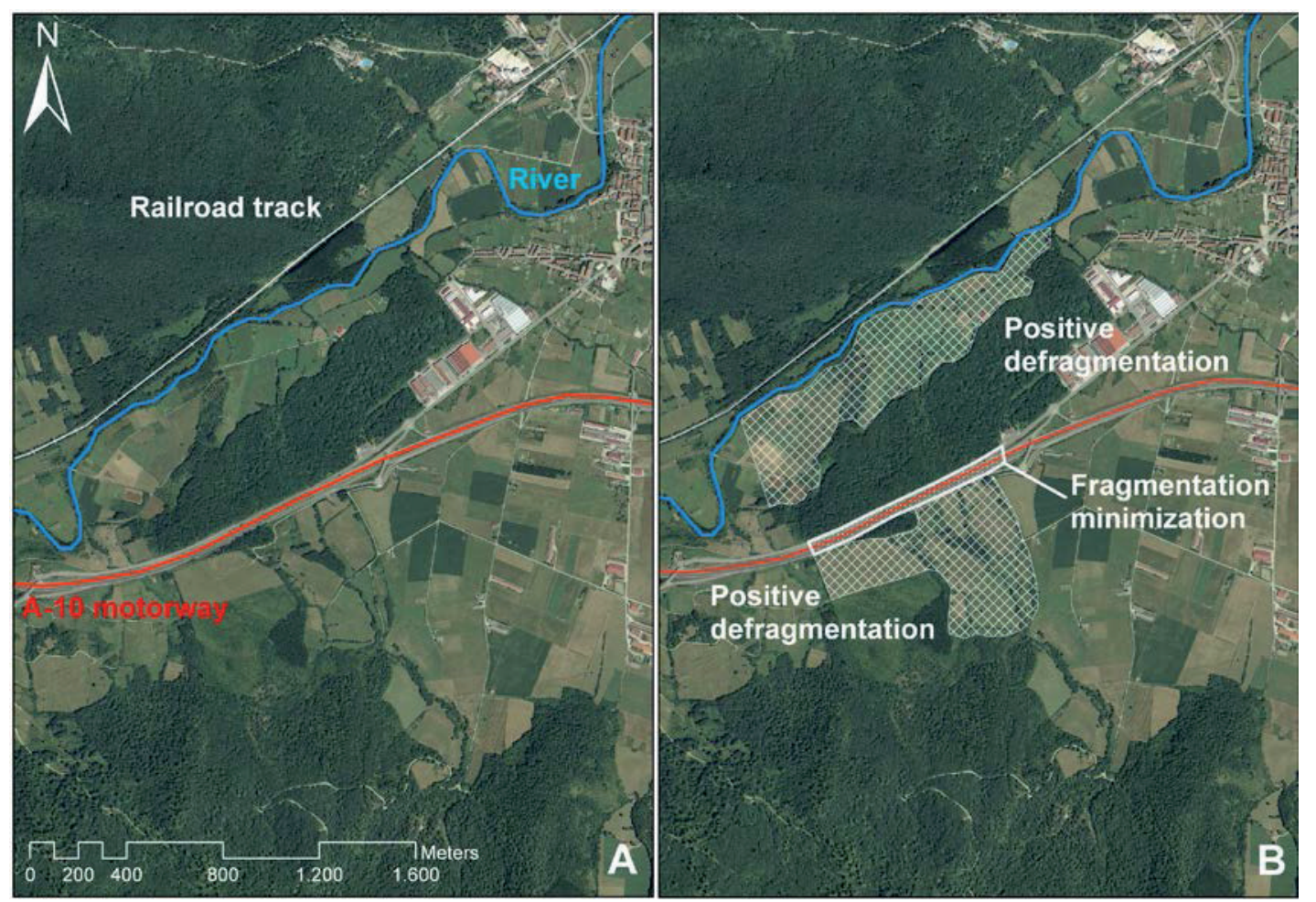

Figure 3. A: Detail of the selected area that shows how the A-10 motorway acts like a fence and even crosses a forested patch at some point between the forested areas of Aralar and Urbasa-Andia. B: Outline of a possible positive defragmentation initiative, including minimization and compensation measures.

\section{Conclusions}

General guidance on ecological compensation can be found in the scientific literature, usually promoting alternative and complementary ways to reach the "no net (ecological) loss" or "net (ecological) gain" principles. The rationale behind each of the general compensation guidelines helps in developing the ecological compensation theory, a necessary step which will eventually result in increased levels of compensation practice. 
But present-day practice is far from attaining the theoretical aims of "no net loss" or "net gain". There is thus a gap between theory and practice which should be progressively narrowed. One of the indicators of this gap is the fact that we usually compromise, by accepting residual impacts on a daily basis during project implementation, even in EIA contexts, as in Spain.

To eliminate this gap between theory and practice, and to move towards more sustainable kinds of development, we propose that general guidance on compensation should be progressively developed. This should be complemented by more concrete proposals on particular kinds of projects, whenever they prove to be usually implemented in an unsustainable way. To improve the sustainability of projects by kinds, we propose to identify those impacted natural features or functions that can be most easily assessed and are most frequently or deeply damaged by the kind of project in question, and set them as priority targets for compensation.

Focusing on road projects, three different kinds of residual impacts have been identified: the loss of natural and semi-natural land-use area, the increase in emissions as a result of the new road, and the fragmentation or barrier effect on the landscape and its wildlife. Four proposals, or "rules", have been advanced to start counteracting these residual impacts in Spain: natural and semi-natural land-use area conservation, conservation of dominant plant species physiognomy, compensation for emissions, and positive defragmentation. As these rules have been devised for the Spanish EIA context, they may require changes or adaptations for alternative countries and contexts. In addition, current regulations in some other countries may be more demanding than those in our country, so it might be necessary to propose stricter goals than those described above in order to promote real change.

If the attempt to promote better compensation practices for road projects fails, or is delayed, the proposed rules may at least help in reminding us how far we fall short from true sustainability when implementing projects.

\section{Acknowledgments}

Special thanks to Dr. Luis Sanz for his photography of the study area. The corresponding author was supported by a doctoral fellowship provided by the Department of Science, Technology and Universities of the Government of the Autonomous region of Aragón. 


\section{References}

Allan JD. Landscapes and riverscapes: The Influence of Land Use on Stream Ecosystems. Annu Rev Ecol Evol Syst 2004;35(I):257-84. DOI:

| 0.1 | 46/annurev.ecolsys.35.120202.1 10122

Blundell AG, Burkey T. Setting biodiversity priorities for biodiversity offsets (open draft for comment). Biodiversity Neutral Initiative; 2006.

van Bohemen HD. Habitat fragmentation, infrastructure and ecological engineering. Ecol Eng 1998; | 1:199-207.

Brinson MM, Rheinhardt R. The Role of Reference Wetlands in Functional Assessment and Mitigation. Ecol Appl 1996;6(I):69-76.

Brownlie S, Botha M. Biodiversity offsets: adding to the conservation estate, or "no net loss"? Impact Assess Proj Apprais 2009:27(3):227-31. DOl: $10.3152 / 146155109 \times 465968$

Business and Biodiversity Offsets Programme (BBOP). Business, Biodiversity Offsets and BBOP. An Overview. 2009a. Available at: http://bbop.foresttrends.org/guidelines/overview.pdf.

Business and Biodiversity Offsets Programme (BBOP). Biodiversity Offset Design Handbook. 2009b. Available at: http://bbop.forest-trends.org/guidelines/odh.pdf.

Cervero R. Road Expansion, Urban Growth, and Induced Travel: A Path Analysis. Institute of Urban and Regional Development, University of California, Berkeley. 200 I. Available at: http://escholarship.org/uc/item/05×370hr,jsessionid=D I 6 7C06A192B5F85CF50470FA84A5B49\#

Chazdon RL. Beyond deforestation: restoring forests and ecosystem services on degraded lands. Science 2008:320(5882):| 458-60. DOl: 10.1 | 26/science. | | 55365

Costanza R, Folke C, Daily GC. Valuing Ecosystem Services with Efficiency, Fairness, and Sustainability as Goals. In: Daily GC, editor. Nature's services: societal dependence on natural ecosystems. Washington DC: Island Press: 1997. p. $49-68$

Cuperus R. Ecological compensation of highway impacts: Negotiated trade-off or no-net-loss? Dissertation (PhD) Leiden University, Institute of Environmental Sciences: 2004.

Cuperus R, Bakermans MMG], Udo de Haes HA, Canters KJ. Ecological Compensation in Dutch Highway Planning. Env Manag 2001;27(1):75-89. DOl: $10.1007 / \mathrm{s} 002670010135$

Cuperus R, Canters KJ, Piepers AAG. Ecological compensation of the impacts of a road. Preliminary method for the A50 road link (Eindhoven-Oss, The Netherlands). Ecol Eng 1996;7:327-49.

Cuperus R, Canters KJ, Udo de Haes HA, Friedman DS. Guidelines for ecological compensation associated with highways. Biol Conserv 1999;90:41-51.

Cuperus R, Kalsbeek M, Udo de Haes HA, Canters KJ. Preparation and Implementation of Seven Ecological Compensation Plans for Dutch Highways. Env Manag 2002;29(6):736-49. DOl: 10.1007/s00267-00 I-2504-7

Dale VH, Brown S, Haeuber RA, Hobbs NT, Huntly N, Naiman RJ, et al. Ecological principles and guidelines for managing the use of land. Ecol Appl 2000; 10(3):639-70.

Darbi M, Ohlenburg $H$, Herberg A, Wende W, Skambraks D, Herbert M. International Approaches to Compensation for Impacts on Biological Diversity. Final Report. Leibniz Institute of Ecological and Regional Development and
Berlin University of Technology, Berlin. 2009. Available at: http://www.forest-

trends.org/publication_details.php?publicationID $=522$

Dolan LMJ, van Bohemen HD, Whelan P, Akbar KF, O'Malley $\checkmark$, O'Leary G, et al. Towards the sustainable development of modern road ecosystems. In: Davenport J, Davenport JL, editors. The Ecology of Transportation: Managing mobility for the Environment. Netherlands: Springer; 2006. p. 275-331.

Environmental Protection Authority (EPA). Environmental Offsets Position Statement No. 9. Government of Western Australia, January 2006. Available at: http://www.epa.wa.gov.au/docs//863_PS9.pdf

European Union (EU). Council Directive 92/43/EEC of 21 May 1992 on the conservation of natural habitats and of wild fauna and flora. May 1992. Available at: http://eurlex.europa.eu/LexUriServ/LexUriServ.do?uri=CELEX:0 | 992L0043-20070 I 0 l:EN:NOT

European Union (EU). Directive 200 I/42/EC of the European Parliament and of the Council on the assessment of the effects of certain plans and programmes on the environment. June 200I. Available at: http://eurlex.europa.eu/LexUriServ/LexUriServ.do?uri=CELEX:32 00 I L0042:EN:NOT

European Union (EU). Directive 2004/35/CE of the European Parliament and of the Council of 2I April 2004 on environmental liability with regard to the prevention and remedying of environmental damage. April 2004. Available at: http://faolex.fao.org/docs/pdf/eur43202.pdf

Fahrig L. Effects of Habitat Fragmentation on Biodiversity. Annu Rev Ecol Evol Syst 2003:34(I):487-5 I 5. DOl: | 0.1 | 46/annurev.ecolsys.34.0 | | 802.1324|9

Foley JA, Defries R, Asner GP, Barford C, Bonan G, Carpenter SR, et al. Global consequences of land use. Science 2005;309(5734):570-4. DOI: 10.1 |26/science. I I I I772

Forman RTT, Alexander LE. Roads and their major ecological effects. Annu Rev Ecol Syst 1998:29:207-31.

Forman RTT, Sperling D, Bissonette JA, Clevenger AP, Cutshall CD, Dale VH, et al. Road ecology. Science and Solutions. Washington DC: Island Press; 2003.

Gibbons P, Lindenmayer DB. Offsets for land clearing: No net loss or the tail wagging the dog? Ecol Manag Restor 2007;8( I):26-31. DOI: 10.1 | | |/j.| 442 8903.2007.00328.x

Goodwin PB. Empirical evidence on induced traffic Transportation 1996;23(I):35-54.

Goodwin PB, Noland RB. Building new roads really does create extra traffic: a response to Prakash et al. Appl Econ 2003:35: | 45 |-7. DOI: 10.1080/0003684032000089872

Hansen AJ, Knight RL, Marzluff JM, et al. Effects of Exurban Development on Biodiversity: Patterns, Mechanisms, and Research Needs. Ecol Appl 2005; I 5(6): I 893-905 DOl: |0.1890/05-522|

Hashisaki S. Functional wetland restoration: an ecosystem approach. Northwest Science 1996;70(4):348-5 I.

Hayes N, Morrison-Saunders A. Effectiveness of environmental offsets in environmental impact assessment: practitioner perspectives from Western Australia. Impact Assess Proj Apprais 2007;25(3):209 | 8. DOI: 10.3152/146155107X227|26

Hoor P, Borken-Kleefeld J. Caro D, et al. The impact of traffic emissions on atmospheric ozone and $\mathrm{OH}$ : results from QUANTIFY. J Atmos Chem Phys 2009;9:31 I3-36. 
Intergovernmental Panel on Climate Change (IPCC). Climate Change 2007: synthesis report. 2007. Available at: http://www.ipcc.ch/publications_and_data/ar4/syr/en/mai n.html

luell B, Bekker H, Cuperus R, Dufek J, Fry G, Hicks C, et al. Wildlife and Traffic: A European Handbook for Identifying Conflicts and Designing Solutions. 2003. Available at:

https://www.milieuinfo.be/productie/beheerplone/nietac $\mathrm{m} /$ iene/cost-34l/european-handbook.

Jongman R. Landscape planning for biological diversity in Europe. Landsc Res 2002;27(2): I 87-95. DOl: 10.1080/0142639022012866

Kalnay E, Cai M. Impact of urbanization and land-use change on climate. Nature 2003;423(May):528-31.

ten Kate K, Bishop J, Bayon R. Biodiversity offsets: Views, experience, and the business case. IUCN. 2004. Available at: http://www.iucn.org/search.cfm?uNewsID=47|

Kiesecker JM, Copeland H, Pocewicz A, McKenney B. Development by design: blending landscape-level planning with the mitigation hierarchy. Front Ecol Environ 2010;8(5):26 I-6. DOI: I0.1890/090005

Koffi B, Szopa S, Cozic A, Hauglustaine D, van Velthoven P. Present and future impact of aircraft, road traffic and shipping emissions on global tropospheric ozone. J Atmos Chem Phys 20 10; 10: I 68 1-705. DOl: 10.5194/acpd-10-15755-2010

Kuiper G. Compensation of environmental degradation by highways: a Dutch case study. Eur Environ 1997;7:I I 825.

Latimer W, Hill D. Mitigation banking: Securing no net loss to biodiversity? A UK perspective. Plan Pract Res 2007;22(2): | 55-75. DOI: | 0. I080/0269745070।584337

Madsen B, Carroll N, Moore Brands K. State of biodiversity markets report: offset and compensation programs worldwide. Ecosystem Marketplace. 20 I0. Available at: http://www.ecosystemmarketplace.com/documents/acro bat/sbdmr.pdf

McKenney B. Environmental offset policies, principles, and methods: a review of selected legislative frameworks. Biodiversity Neutral Initiative. 2005. Available at: http://www.foresttrends.org/publication_details.php?publicationID =54 I

McKenney BA, Kiesecker JM. Policy development for biodiversity offsets: a review of offset frameworks. Environ Manag 20 10;45( I): 1 65-76. DOI: 10.1007/s00267-009-9396-3

van Merwyk T, Daddo S. Structuring Environmental Offsets for a Sustainable Advantage. Undated. Available at http://foresttrends.org/publication_details.php?publication ID =582

Mitsch WJ, Wilson RF. Improving the Success of Wetland Creation and Restoration with Know-How, Time and Self-Design. Ecol Appl 1996;6(I):77-83.

Moilanen A, van Teeffelen AJA, Ben-Haim Y, Ferrier S. How Much Compensation is Enough? A Framework for Incorporating Uncertainty and Time Discounting When Calculating Offset Ratios for Impacted Habitat. Restor Ecol 2009; I7(4):470-8. DOl: 10.1 I I I/j. I526100X.2008.00382.X

Morris RKA, Alonso I, Jefferson RG, Kirby KJ. The creation of compensatory habitat - Can it secure sustainable development? J Nat Conserv 2006; I 4: I 06-16. DOI: 10.1016/j.jnc.2006.01.003
National Research Council (NRC). Compensating for wetland losses under the Clean Water Act. Washington, D.C.: National Academy Press; 2001.

Penny Anderson Associates (PAA). Roads and nature conservation: guidance on impacts, mitigation and enhancement. Peterborough: English Nature Publicity; 1993.

Pope J, Annandale D, Morrison-Saunders A. Conceptualising sustainability assessment. Environ Impact Assess Rev 2004:24:595-616. DOl: 10.10 16/j.eiar.2004.03.00 I

Poschlod P, Bakker JP, Kahmen S. Changing land use and its impact on biodiversity. Basic Appl Ecol 2005:6(2):93-8. DOI: 10.1016/j.baae.2004.12.00।

Race MS, Fonseca MS. Fixing Compensatory Mitigation: What Will it Take? Ecol Appl 1996;6(I):94-101.

Reijnen R, Foppen R. Impact of road traffic on breeding bird populations. In: Davenport J, Davenport JL, editors. The Ecology of Transportation: Managing Mobility for the Environment. Vol I0. Heidelberg: Springer-Verlag; 2006 p. $255-274$.

Riitters $\mathrm{KH}$, Wickham JD. How far to the nearest road? Front Ecol Environ 2003; I (3): I25-9. DOl: 10.2307/3867984

Rowe DK, Parkyn S, Quinn J, Collier K, Hatton C, Joy MK, et al. A rapid method to score stream reaches based on the overall performance of their main ecological functions. Environ Manag 2009;43(6): | 287-300. DOI: 10.1007/s00267-009-9302-z

Sala OE, Stuart Chapin III F, Armesto JJ, Berlow E, Bloomfield J. Dirzo R, et al. Global biodiversity scenarios for the year 2 I00. Science 2000;287(5459): 1770.

Saunders DA, Hobbs RJ, Margules CR. Biological consequences of ecosystem fragmentation: a review. Conserv Biol 1991;5(1):18-32.

Tong S, Chen W. Modeling the relationship between land use and surface water quality. I Environ Manag 2002;66(4):377-93. DOI: 10.1006/jema.2002.0593

Trocmé M. Habitat Fragmentation due to Linear Transportation Infrastructure: An overview of mitigation measures in Switzerland. Proceedings from the 6th Swiss Transport Research Conference; 15/17 March 2006. Available at: http://www.thepep.org/ClearingHouse/docfiles/Trocme_ fragmentation switzerland.pdf

Trocmé M, Cahill S, de Vries JG, Farrall H, Folkeson LG, Hichks C, et al. COST 34I - Habitat Fragmentation due to Transportation Infrastructure: The European Review. Office for official publications of the European Communities, Luxembourg. Available at: https://www.milieuinfo.be/productie/beheerplone/nietac m/iene/cost-34I/SotA-COST34 IER03 I 8.pdf

United States Congress (USC). Federal Water Pollution Control Act (as amended through P.L. 107-303, November 27, 2002). 2002. Available at: http://epw.senate.gov/water.pdf

Villarroya A, Puig J. Ecological compensation and Environmental Impact Assessment in Spain. Environ Impact Assess Rev 20 10;30(6):357-62. DOl: 10.1016/j.eiar.2009.1 1.001

Vitousek PM, Mooney HA, Lubchenco J, Melillo JM. Human domination of Earth's ecosystems. Science 1997;277(5325):494. 